\title{
Genetic risk factors in Finnish patients with Parkinson's disease
}

\section{Ylönen, Susanna}

2017-09-29

Ylönen , S , Siitonen , A , Nalls , M A , Ylikotila , P , Autere , J , Eerola-Rautio , J , Gibbs , R , Hiltunen, M , Tienari , P J , Soininen , H , Singleton , A B \& Majamaa , K 2017 , ' Genetic risk factors in Finnish patients with Parkinson's disease ', Parkinsonism \& Related Disorders . https://doi.org/10.1016/j.parkreldis.2017.09.021

http://hdl.handle.net/10138/298404

https://doi.org/10.1016/j.parkreldis.2017.09.021

publishedVersion

Downloaded from Helda, University of Helsinki institutional repository.

This is an electronic reprint of the original article.

This reprint may differ from the original in pagination and typographic detail.

Please cite the original version. 


\title{
Genetic risk factors in Finnish patients with Parkinson's disease
}

\author{
Susanna Ylönen ${ }^{\mathrm{a}, \mathrm{b}}$, Ari Siitonen ${ }^{\mathrm{a}, \mathrm{b}}$, Michael A. Nalls ${ }^{\mathrm{c}}$, Pauli Ylikotila ${ }^{\mathrm{d}, \mathrm{e}}$, Jaana Autere ${ }^{\mathrm{f}}$, \\ Johanna Eerola-Rautio ${ }^{g}$, Raphael Gibbs ${ }^{c}$, Mikko Hiltunen ${ }^{\text {h}}$, Pentti J. Tienari ${ }^{g}$, \\ Hilkka Soininen ${ }^{\mathrm{h}}$, Andrew B. Singleton ${ }^{\mathrm{c}}$, Kari Majamaa a, b, * \\ a Institute of Clinical Medicine, Department of Neurology, University of Oulu, Oulu, Finland \\ ${ }^{\mathrm{b}}$ Department of Neurology and Medical Research Center, Oulu University Hospital, Oulu, Finland \\ c Laboratory for Neurogenetics, National Institute on Aging, National Institutes of Health, Bethesda, MD, USA \\ d Institute of Clinical Medicine, Department of Neurology, University of Turku, Turku, Finland \\ e Division of Clinical Neurosciences, Turku University Hospital, Turku, Finland \\ ${ }^{\mathrm{f}}$ Neuro Center, Kuopio University Hospital, Kuopio, Finland \\ ${ }^{\mathrm{g}}$ Department of Neurology, Helsinki University Hospital, Research Programs Unit, Molecular Neurology, Biomedicum, University of Helsinki, Helsinki FIN- \\ 02900, Finland \\ ${ }^{\mathrm{h}}$ Faculty of Health Sciences, University of Eastern Finland, Kuopio, Finland
}

\section{A R T I C L E I N F O}

\section{Article history:}

Received 18 July 2017

Received in revised form

30 August 2017

Accepted 28 September 2017

\section{Keywords:}

Molecular epidemiology

Neurodegenerative diseases

Mutation

Mitochondrial

Gene

\begin{abstract}
A B S T R A C T
Introduction: Variation contributing to the risk of Parkinson's disease (PD) has been identified in several genes and at several loci including GBA, SMPD1, LRRK2, POLG1, CHCHD10 and MAPT, but the frequencies of risk variants seem to vary according to ethnic background. Our aim was to analyze how variation in these genes contributes to PD in the Finnish population.

Methods: The subjects consisted of 527 Finnish patients with early-onset PD, 325 patients with lateonset PD and 403 population controls. We screened for known genetic risk variants in GBA, SMPD1, LRRK2, POLG1, CHCHD10 and MAPT. In addition, DNA from 225 patients with early-onset Parkinson's disease was subjected to whole exome sequencing (WES).

Results: We detected a significant difference in the length variation of the CAG repeat in POLG1 between patients with early-onset PD compared to controls. The p.N370S and p.L444P variants in GBA contributed to a relative risk of 3.8 in early-onset PD and 2.5 in late-onset PD. WES revealed five variants in $L R R K 2$ and SMPD1 that were found in the patients but not in the Finnish ExAC sequences. These are possible risk variants that require further confirmation. The p.G2019S variant in LRRK2, common in North African Arabs and Ashkenazi Jews, was not detected in any of the 849 PD patients.

Conclusions: The POLG1 CAG repeat length variation and the GBA p.L444P variant are associated with PD in the Finnish population.
\end{abstract}

(c) 2017 Elsevier Ltd. All rights reserved.

\section{Introduction}

Genetic variation contributing to the risk of Parkinson's disease (PD) has been identified. One of the genes involved is glucosylceramidase beta $(G B A)$ that codes for a lysosomal enzyme. It is traditionally associated with Gaucher's disease, but heterozygous mutations are an established risk factor for Parkinson's disease. The two most common mutations in GBA include p.L444P and p.N370S.

\footnotetext{
* Corresponding author. University of Oulu, Department of Neurology, P.O. Box 5000, FIN-90014 Oulu, Finland.

E-mail address: kari.majamaa@oulu.fi (K. Majamaa).
}

SMPD1 encodes another gene involved in lysosomal function. It codes for the protein sphingomyelin phosphodiesterase 1 that generates ceramide by cleaving the phosphocholine group of sphingomyelin. Mutations in SMPD1 are found in Niemann-Pick disease and the variant p.L302P has been suggested to be associated with PD [1].

The LRRK2 (leucine-rich repeat kinase 2) gene encodes a 2527amino acid protein with several structural and functional domains such as leucine-rich repeat and kinase. The common p.G2019S mutation is located in the kinase domain and it has been shown to increase the kinase activity [2]. The frequency of the p.G2019S mutation varies greatly in different populations being most common in North African Arabs, where it is found in 39\% of sporadic 
and $36 \%$ of familial cases, and Ashkenazi Jews, where it is found in $10 \%$ of sporadic and $28 \%$ of familial cases. Among Europeans, the frequency is $4 \%$ in sporadic cases in Portugal and $14 \%$ in familial cases, whereas in Spain, Italy and France it is $2-4 \%$, and in Sweden and Norway the frequency is $1 \%$. In Asian countries the mutation is very rare being found in $<0.1 \%$ of patients [3]. The penetrance of p.G2019S is high, but not complete, so that the risk of PD is $74 \%$ at the age of 79 years [3].

Other genes, where variation may contribute to the risk of PD, include POLG1, CHCHD10 and MAPT. Polymerase $\gamma$ (POLG1) is responsible for the replication of the mitochondrial genome. The second exon of the gene harbors a microsatellite consisting of ten CAG trinucleotide repeats that is translated into a tract of ten glutamine moieties (10Q). Genotypes different from the common $10 \mathrm{Q}$ variant have been associated with a higher risk of PD [4]. CHCHD10 encodes a coiled-coil helix coiled-coil helix protein that is involved in the maintenance of mitochondrial cristae integrity [5]. The variant p.S59L in CHCHD10 has been associated with a complex phenotype consisting of amyotrophic lateral sclerosis, frontotemporal lobar degeneration, cerebellar ataxia, parkinsonism, and myopathy [5] and, subsequently, another variant p.G66V has been identified [6]. MAPT (microtubule-associated protein tau) is involved in the assembly and stabilization of microtubules. Of the two haplotypes $\mathrm{H} 1$ and $\mathrm{H} 2$, haplotype $\mathrm{H} 1$ has been reported to be slightly more common in PD patients than in population controls [7].

Previous data have shown that the frequencies of these mutations in patients with PD vary according to ethnic background [8]. Therefore, we screened for the most common known mutations in the genes GBA, SMPD1, LRRK2 and CHCHD10, determined the length variation in POLG1 and determined the MAPT haplotype in Finnish patients with Parkinson's disease and population controls.

\section{Subjects and methods}

\subsection{Patients and controls}

The study group consisted of a national cohort of 441 patients with EOPD defined by age of onset $<55$ years [9]. In addition, a case series collected at the Kuopio University Hospital during one year [10] comprised of 209 patients with late-onset Parkinson's disease (LOPD) and 55 patients with EOPD, and a case series collected at the Helsinki University Hospital [4] comprised 116 patients with LOPD and 31 patients with EOPD. Previous analyses on these cohorts have not revealed causative mutations in the common PD genes. Controls consisted of 403 healthy blood donors from three different regions of Finland. Part of the samples in the national cohort of EOPD $(N=225)$ were subjected to whole exome sequencing (WES). The study has been approved by the Ethics Committee of Turku University Hospital, the Ethics Committee of the Medical Faculty of the University of Kuopio, the Ethics Committee of Helsinki University Hospital and the Ethics committee of the Finnish Red Cross. Written informed consent was obtained from all patients prior to participating the study.

\subsection{Molecular methods}

Genomic DNA was extracted from peripheral blood using standard protocols. The variations in GBA (p.N370S, p.L444P), SMPD1 (p.L302P), LRRK2 (p.R1441C/G/H, p.G2019S), CHCHD10 (p.S59L, p.G66V) and MAPT (haplotype H1) were detected using a PCRrestriction digestion protocol. The primers and restriction enzymes used are presented in supplementary table. The detected variations were confirmed by sequencing.

The CAG repeat in exon 2 of the POLG1 gene was analyzed by fragment length analysis. A fragment containing the CAG repeat was amplified using a FAM-labeled forward primer CTCCGAGGATAGCACTTGC and a reverse primer CTGGGTCTCCAGCTCCGT (CHLC.GCT14A01.P16693.1 and CHLC.GCT14A01.P16693.2, respectively; GenBank accession number G16014). The fragment length was $124 \mathrm{bp}$ in the presence of the most common allele containing ten CAG repeats. The fluorescent-labeled PCR products in the EOPD group were separated on an ABI PRISM ${ }^{\mathbb{B}} 3100$ Genetic Analyzer (Perkin Elmer, Foster City, CA, U.S.A.). GeneScan ${ }^{\mathrm{TM}}-500$ LIZ $^{\circledR}$ Size Standard (Applied Biosystems, Foster City, CA, U.S.A.) was used as an internal standard and was run along with each sample. The alleles were identified using the Peak Scanner ${ }^{\mathrm{TM}}$ Software Version 1.0 (Applied Biosystems). In the LOPD group and the controls an ABI PRISM $^{\text {TM }} 377$ DNA Sequencer (Perkin Elmer) was used with Genescan version 2.1 fragment analysis software (Perkin Elmer). GENESCAN-500 TM TAMRA (Applied Biosystems) was used as an internal standard and the Genotyper 2.0 program (Perkin Elmer) was used for identifying the alleles.

WES was carried out as described previously [11]. Annovar [12], SNPEff [13] and SNPSift [14] were used for functional annotations. The data were unfiltered so that even the unlikely SNPs could be detected. As controls we used 563 STAMPEED population controls from the North Finland Birth Cohort 1966. WES has recently revealed several mutations, but no splice mutations, in established EOPD genes among the 225 EOPD patients [11]. Clinical significance of the mutations is, however, unknown. Nonsynonymous mutations in LRRK2 and SMPD1 that were more frequent among the patients than among the controls were verified by direct sequencing and were analysed for their pathogenic potential by using PredictSNP [15].

\subsection{Statistical analysis}

Fisher exact test was used to compare allele frequencies between patients and controls. The frequency distribution of the CAG repeat alleles in the POLG1 gene was analyzed with the exact test of population differentiation using the Arlequin software [16].

\section{Results}

\subsection{Genetic variants contributing to the risk of EOPD}

None of the EOPD patients harbored SMPD1 p.L302P, LRRK2 p.R1441C/G/H, LRRK2 p.G2019S, CHCHD10 p.S59L or CHCHD10 p.G66V. The frequency of haplotype $\mathrm{H} 1$ in MAPT was $92.6 \%$ in the patients and $95.0 \%$ in the 292 controls ( $\mathrm{p}=0.068$ for difference, Table 1). The length of the CAG repeat in the POLG1 gene varied between $8 \mathrm{Q}$ and $13 \mathrm{Q}$ in the EOPD patients and between $8 \mathrm{Q}$ and $12 \mathrm{Q}$ in the controls. The frequency distribution of the CAG repeat alleles

Table 1

MAPT $\mathrm{H} 1 / \mathrm{H} 2$ genotype and allele distribution.

\begin{tabular}{lllll}
\hline (A) Genotypes & $\mathrm{H} 1 / \mathrm{H} 1$ & $\mathrm{H} 1 / \mathrm{H} 2$ & $\mathrm{H} 2 / \mathrm{H} 2$ & Total \\
& $\mathrm{N}(\%)$ & $\mathrm{N}(\%)$ & $\mathrm{N}(\%)$ & $\mathrm{N}$ \\
\hline Controls & $263(90.1)$ & $29(9.9)$ & 0 & 292 \\
EOPD & $452(86.1)$ & $68(13.0)$ & $5(1.0)$ & 525 \\
LOPD & $290(89.8)$ & $30(9.3)$ & $3(0.9)$ & 323 \\
& & & \\
(B) Alleles & $\mathrm{H} 1$ & $\mathrm{H} 2$ & \\
& $\mathrm{~N}(\%)$ & $\mathrm{N}(\%)$ & \\
\hline Controls & $555(95.0)$ & & $29(5.0)$ & 584 \\
EOPD & $972(92.6)$ & & $78(7.4)$ & 1050 \\
LOPD & $610(94.4)$ & & $36(5.6)$ & 646 \\
\hline
\end{tabular}

EOPD, early-onset Parkinson's disease; LOPD, late-onset Parkinson's disease. 
in POLG1 differed between the EOPD patients and the controls ( $\mathrm{p}=0.041$, exact test of population differentiation). The frequency of non-10Q alleles was $10.7 \%$ in the EOPD patients (Table 2) and $6.8 \%$ in the controls ( $\mathrm{p}=0.0056$ for difference). Seven EOPD patients harbored a non-10Q/non-10Q genotype, while none of the controls had such a genotype. The clinical features, age of PD onset and the frequency of family history did not differ between EOPD patients harboring a non-10Q/non-10Q genotype $(\mathrm{n}=7)$ and EOPD patients with $10 \mathrm{Q} / 10 \mathrm{Q}$ genotype $(\mathrm{n}=397)$. However, postural instability and on-off variation was less common in patients with non-10Q/non-10Q genotype.

Two EOPD patients and one control had the heterozygous p.N370S mutation in GBA and 13 patients and two controls had the heterozygous p.L444P mutation ( $\mathrm{p}=0.032$, Fisher's exact test, Table 3). One of the patients with p.N370S also had the POLG1 variants p.N468D and p.A1105T that has been reported previously [17]. Three of the patients with p.L444P in GBA also had the nonsynonymous p.A456P variant and the synonymous rs 1135675 variant at codon 460, which in combination with p.L444P form the RecNcil allele.

\subsection{Genetic variants contributing to the risk of late-onset PD}

The five mutations in SMPD1, LRRK2 or CHCHD10 were not found in 323 LOPD patients. The frequency of haplotype H1 in MAPT was $94.4 \%$ in LOPD patients ( $\mathrm{p}=0.73$ for difference, Table 1$)$. Two LOPD patients had the heterozygous p.N370S mutation and four patients had the heterozygous p.L444P mutation in GBA (Table 3). Interestingly, one patient had both p.L444P and p.N370S mutations. The frequency distribution of the CAG repeat alleles in the POLG1 gene did not differ between the LOPD patients and the controls $(\mathrm{p}=0.13$, exact test of population differentiation, Table 2). The frequency of the POLG1 non-10Q alleles was $7.9 \%$ in LOPD and three LOPD patients harbored a non-10Q/non-10Q genotype.

\subsection{Variation in WES in GBA, MAPT, SMPD1, LRRK2}

As the well-known variants in LRRK2 and SMPD1 were not

Table 2

Frequencies of POLG1 CAG repeat length genotypes and alleles in patients with PD and controls.

\begin{tabular}{|c|c|c|c|c|c|c|}
\hline \multirow{2}{*}{ Genotype } & \multicolumn{2}{|c|}{ EOPD } & \multicolumn{2}{|c|}{ LOPD } & \multicolumn{2}{|c|}{ Controls } \\
\hline & $\mathrm{N}$ & $\%$ & $\mathrm{~N}$ & $\%$ & $\mathrm{~N}$ & $\%$ \\
\hline $8 / 10$ & 3 & 0.6 & 2 & 1.0 & 3 & 0.7 \\
\hline $8 / 11$ & 1 & 0.2 & 1 & 0.5 & 0 & \\
\hline $9 / 9$ & 1 & 0.2 & 0 & & 0 & \\
\hline $9 / 10$ & 22 & 4.4 & 10 & 4.8 & 11 & 2.7 \\
\hline $9 / 11$ & 1 & 0.2 & 1 & 0.5 & 0 & \\
\hline $9 / 12$ & 1 & 0.2 & 0 & & 0 & \\
\hline $10 / 10$ & 397 & 80.0 & 179 & 85.6 & 348 & 86.4 \\
\hline $10 / 11$ & 56 & 11.3 & 11 & 5.3 & 31 & 7.7 \\
\hline $10 / 12$ & 10 & 2.0 & 2 & 1.0 & 10 & 2.5 \\
\hline $10 / 13$ & 1 & 0.2 & 2 & 1.0 & 0 & \\
\hline $11 / 11$ & 2 & 0.4 & 1 & 0.5 & 0 & \\
\hline $11 / 13$ & 1 & 0.2 & 0 & & 0 & \\
\hline All & 496 & & 209 & & 403 & \\
\hline $\begin{array}{l}\text { non-10/non-10 } \\
\text { Allele }\end{array}$ & 7 & 1.4 & 3 & 1.4 & 0 & \\
\hline 8 & 4 & 0.4 & 3 & 0.7 & 3 & 0.4 \\
\hline 9 & 26 & 2.6 & 11 & 2.6 & 11 & 1.4 \\
\hline 10 & 886 & 89.3 & 385 & 92.1 & 751 & 93.2 \\
\hline 11 & 63 & 6.4 & 15 & 3.6 & 31 & 3.9 \\
\hline 12 & 11 & 1.1 & 2 & 0.5 & 10 & 1.2 \\
\hline 13 & 2 & 0.2 & 2 & 0.5 & 0 & \\
\hline All & 992 & & 418 & & 806 & \\
\hline non-10 & 106 & 10.7 & 33 & 7.9 & 55 & 6.8 \\
\hline
\end{tabular}

EOPD, early-onset Parkinson's disease; LOPD, late-onset Parkinson's disease.
Table 3

Frequencies of GBA mutations in patients with PD and controls.

\begin{tabular}{llll}
\hline Mutation & EOPD N (\%) & LOPD N (\%) & Controls N (\%) \\
\hline p.N370S & $2(0.4)$ & $2(0.6)$ & $1(0.3)$ \\
p.L444P & $13(2.5)$ & $4(1.2)$ & $2(0.5)$ \\
\hline
\end{tabular}

EOPD, early-onset Parkinson's disease; LOPD, late-onset Parkinson's disease.

detected in the Finnish patients with EOPD, we then selected randomly 225 out of the 441 samples to WES. Rare variation was detected in LRRK2 and SMPD1 (Table 4), where we found five nonsynonymous variants that were present in patients but not in Finnish ExAC controls. Two variants were deemed to be deleterious (Table 4) and, interestingly, the p.R542Q variant in SMPD1 was homozygous and the p.R1628P in LRRK2 has previously been reported in association with PD [18].

\section{Discussion}

We detected a significant difference in POLG1 CAG repeat length variation between the patients with EOPD and the controls and in the frequency of the GBA variant p.L444P. The p.G2019S variant in LRRK2 was not found among Finnish PD patients, although it has previously been found in European PD patients and is especially common among North African Arab and Ashkenazi Jewish PD patients [3]. WES revealed several variants in LRRK2 and SMPD1 that were found only in PD patients and not in the controls. These are putative risk variants, but require further confirmation.

The two most common mutations p.L444P and p.N370S comprise more than $50 \%$ of the pathogenic mutations in GBA. The allele frequency of the two mutations is high among Ashkenazi Jewish PD patients with a total frequency of $15.3 \%$. The combined frequency of the two mutations is approximately $3.2 \%$ in nonAshkenazi Jewish PD patients [8], 2.3\% in Norwegian patients [8] and $2.8 \%$ in Swedish patients [19], whereas among non-Finnish Europeans in the ExAC database the frequency is $0.8 \%$. We found these $G B A$ mutations in $2.8 \%$ of the EOPD patients giving a relative risk of 3.8 for PD and in $1.9 \%$ of the LOPD patients giving a relative risk of 2.5. Patients with a GBA mutation appear to have an earlier onset of PD compared to that in patients without mutations [8]. In Finnish EOPD patients with a GBA mutation the mean age of onset was 44.6 years and at least five out of the 15 mutation carriers reported $\mathrm{PD}$ in a first-degree relative.

The variants p.G2019S in LRRK2 and p.L302P in SMPD1 are associated with increased risk of PD $[1,20]$. We did not find these variants in our samples, but WES revealed five other variants that were not found in the controls. PredictSNP suggested that the LRRK2 variant p.R1628P is deleterious. This variant has been previously associated with PD in Chinese and Thai populations [18]. The p.R1628P variant acts by turning its adjacent amino acid residue S1627 to a new phosphorylation site of Cdk5. Cdk5 phosphorylation of p.S1627 in the presence of p.R1628P increases the LRRK2 kinase activity. Interestingly, cultured mouse cortical neurons transfected with p.R1628P LRRK2 plasmids show a higher sensitivity of to MPP+ [21]. Our two patients with p.R1628P had an age of onset of 44 and 49 years and had no family history of PD.

The homozygous SMPD1 p.L302P mutation causes a fatal infantile type A Niemann-Pick disease. This mutation in heterozygous state has previously been shown to be associated with Parkinson's disease [1]. We did not find p.L302P among Finnish PD patients, but WES revealed two other variants that were not found in controls. PredictSNP suggested that the SMPD1 variant p.R542Q was deleterious, while p.E358K was neutral. The frequency of p.R542Q is 
Table 4

Rare variants in exome sequences of LRRK2 and SMPD1.

\begin{tabular}{|c|c|c|c|c|c|c|c|c|c|c|}
\hline \multirow[t]{2}{*}{ Gene } & \multirow[t]{2}{*}{ Position } & \multirow[t]{2}{*}{ Ref } & \multirow[t]{2}{*}{ Alt } & \multirow[t]{2}{*}{ dbSNP } & \multirow[t]{2}{*}{ Amino acid change } & \multicolumn{2}{|c|}{ PredictSNP } & \multirow[t]{2}{*}{ Patients with variant (n) } & \multicolumn{2}{|c|}{$\begin{array}{l}\text { Finnish alleles in ExAC } \\
(\mathrm{n})\end{array}$} \\
\hline & & & & & & Effect & Accuracy (\%) & & All & With variant \\
\hline \multicolumn{11}{|c|}{ Variants not present in controls } \\
\hline SMPD1 & 6413367 & G & A & n.a. & p.E358K & $\mathrm{N}$ & 63 & 1 & 6558 & 0 \\
\hline SMPD1 & 6415566 & G & A & rs113467489 & p.R542Q & $\mathrm{D}$ & 65 & 1 & 6614 & 0 \\
\hline LRRK2 & 40693018 & G & $\mathrm{T}$ & n.a. & p.C1152F & $\mathrm{N}$ & 75 & 1 & n.d. & n.d. \\
\hline LRRK2 & 40713842 & $\mathrm{C}$ & $\mathrm{T}$ & rs201637880 & p.S1627L & $\mathrm{N}$ & 83 & 1 & n.d. & n.d. \\
\hline LRRK2 & 40713845 & G & $\mathrm{C}$ & rs33949390 & p.R1628P & $\mathrm{D}$ & 72 & 2 & 6610 & 0 \\
\hline
\end{tabular}

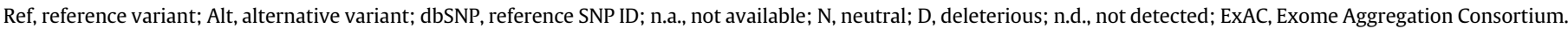

6.0/100,000 among non-Finnish Europeans in the ExAC database and, interestingly, the patient was homozygous. Clinically the patient with p.R542Q was unremarkable with an age of onset of 54 years and with no family history of PD. Homozygous p.R608del mutation has been described previously in a patient with PD and type B Niemann-Pick disease [22].

The length of the CAG repeat in POLG1 varies between 5 and 16 trinucleotides $[23,24]$. We detected a difference in the repeat allele distribution between EOPD patients and controls and a difference in the frequency of non-10Q alleles. A difference in the frequency of non-10/11Q alleles has previously been obtained in Finnish [4], Swedish [23], Norwegian [24] and Chinese populations [25], but not among North American Caucasians [26]. The latter study, however, reported a higher frequency of non-10Q alleles among PD patients, whereas no difference has been found in this frequency between Australian PD patients and controls [27]. These associations suggest that polymerase $\gamma$ protein harboring the non-10Q stretch contributes directly to the risk of PD or that the non-10 CAG repeat alleles represent markers of harmful variants elsewhere in the gene. The protein harboring a non-10Q polyglutamine tract could be less optimal in protein-protein interactions [28]. Furthermore, estimation of mRNA folding energies in silico has shown that the folding energy is lower in the shorter POLG variants and higher in the longer variants [23].

We found that there are common alleles in the Finnish population that increase the risk of PD. The POLG1 non-10Q variants were associated with an increased risk of PD and the GBA p.L444P variant contributed to a relative risk of 4.9 with respect to EOPD. Interestingly, we did not detect the p.G2019S variant in LRRK2 that is common in other populations, but WES revealed other variants in this gene and in SMPD1 that were found only in PD patients suggesting that they are putative risk variants.

\section{Author contributions}

S. Ylönen, study design, genetic analysis, writing the manuscript; A. Siitonen, whole exome sequencing; M.A. Nalls, whole exome sequencing; P. Ylikotila, sample collection, clinical analysis; J. Autere, sample collection; J. Eerola-Rautio, sample collection; R. Gibbs, whole exome sequencing; M. Hiltunen, sample collection; P.J. Tienari, sample collection; H. Soininen, sample collection; A.B. Singleton, whole exome sequencing; and K. Majamaa, study design, data analysis, statistical analysis, writing the manuscript, study supervision. All authors contributed to the conception of the study, revising the manuscript for intellectual content and approved the final version for publication.

\section{Conflicts of interest}

None.

\section{Acknowledgements}

This study was supported in part by grants from the Sigrid Juselius Foundation, the Finnish Brain Foundation, the Finnish Parkinson Foundation and the Intramural Research Program of the National Institute on Aging, National Institutes of Health, part of the Department of Health and Human Services; project ZO1 AG000949. None of the funding sources had any influence on the study design, execution or interpretation, writing of the manuscript or decision to submit the paper for publication. The expert technical assistance of Ms. Anja Heikkinen and Ms. Pirjo Keränen is acknowledged.

\section{Appendix A. Supplementary data}

Supplementary data related to this article can be found at https://doi.org/10.1016/j.parkreldis.2017.09.021.

\section{References}

[1] Z. Gan-Or, L.J. Ozelius, A. Bar-Shira, R. Saunders-Pullman, A. Mirelman, R. Kornreich, M. Gana-Weisz, D. Raymond, L. Rozenkrantz, A. Deik, T. Gurevich, S.J. Gross, N. Schreiber-Agus, N. Giladi, S.B. Bressman, A. OrrUrtreger, The p.L302P mutation in the lysosomal enzyme gene SMPD1 is a risk factor for Parkinson disease, Neurology 80 (2013) 1606-1610.

[2] O. Corti, S. Lesage, A. Brice, What genetics tells us about the causes and mechanisms of Parkinson's disease, Physiol. Rev. 91 (2011) 1161-1218.

[3] D.G. Healy, M. Falchi, S.S. O'Sullivan, V. Bonifati, A. Durr, S. Bressman, A. Brice, J. Aasly, C.P. Zabetian, S. Goldwurm, J.J. Ferreira, E. Tolosa, D.M. Kay, C. Klein, D.R. Williams, C. Marras, A.E. Lang, Z.K. Wszolek, J. Berciano, A.H. Schapira T. Lynch, K.P. Bhatia, T. Gasser, A.J. Lees, N.W. Wood, Phenotype, genotype, and worldwide genetic penetrance of LRRK2-associated Parkinson's disease: case-control study, Lancet Neurol. 7 (2008) 583-590.

[4] P.T. Luoma, J. Eerola, S. Ahola, A.H. Hakonen, O. Hellström, K.T. Kivistö P.J. Tienari, A. Suomalainen, Mitochondrial DNA polymerase gamma variants in idiopathic sporadic Parkinson disease, Neurology 69 (2007) 1152-1159.

[5] S. Bannwarth, S. Ait-El-Mkadem, A. Chaussenot, E.C. Genin, S. Lacas-Gervais K. Fragaki, L. Berg-Alonso, Y. Kageyama, V. Serre, D.G. Moore, A. Verschueren, C. Rouzier, I. Le Ber, G. Augé, C. Cochaud, F. Lespinasse, K. N'Guyen, A. de Septenville, A. Brice, P. Yu-Wai-Man, H. Sesaki, J. Pouget, V. Paquis-Flucklinger A mitochondrial origin for frontotemporal dementia and amyotrophic lateral sclerosis through CHCHD10 involvement, Brain 137 (2014) 2329-2345.

[6] S. Penttilä, M. Jokela, H. Bouquin, A.M. Saukkonen, J. Toivanen, B. Udd, Late onset spinal motor neuronopathy is caused by mutation in CHCHD10, Ann. Neurol. 77 (2015) 163-172.

[7] C.P. Zabetian, C.M. Hutter, S.A. Factor, J.G. Nutt, D.S. Higgins, A. Griffith, J.W. Roberts, B.C. Leis, D.M. Kay, D. Yearout, J.S. Montimurro, K.L. Edwards A. Samii, H. Payami, Association analysis of MAPT H1 haplotype and subhaplotypes in Parkinson's disease, Ann. Neurol. 62 (2007) 137-144.

[8] E. Sidransky, M.A. Nalls, J.O. Aasly, J. Aharon-Peretz, G. Annesi, E.R. Barbosa A. Bar-Shira, D. Berg, J. Bras, A. Brice, C.M. Chen, L.N. Clark, C. Condroyer E.V. De Marco, A. Dürr, M.J. Eblan, S. Fahn, M.J. Farrer, H.C. Fung, Z. Gan-Or, T. Gasser, R. Gershoni-Baruch, N. Giladi, A. Griffith, T. Gurevich, C. Januario P. Kropp, A.E. Lang, G.J. Lee-Chen, S. Lesage, K. Marder, I.F. Mata, A. Mirelman, J. Mitsui, I. Mizuta, G. Nicoletti, C. Oliveira, R. Ottman, A. Orr-Urtreger L.V. Pereira, A. Quattrone, E. Rogaeva, A. Rolfs, H. Rosenbaum, R. Rozenberg A. Samii, T. Samaddar, C. Schulte, M. Sharma, A. Singleton, M. Spitz, E.K. Tan, N. Tayebi, T. Toda, A.R. Troiano, S. Tsuji, M. Wittstock, T.G. Wolfsberg, Y.R. Wu, C.P. Zabetian, Y. Zhao, S.G. Ziegler, Multicenter analysis of glucocerebrosidase mutations in Parkinson's disease, N. Engl. J. Med. 361 (2009) 1651-1661.

[9] P. Ylikotila, T. Tiirikka, J.S. Moilanen, H. Kääriäinen, R. Marttila, K. Majamaa, Epidemiology of early-onset Parkinson's disease in Finland, Park. Relat. Disord. 
21 (2015) 938-942

[10] J. Autere, J.S. Moilanen, S. Finnilä, H. Soininen, A. Mannermaa, P. Hartikainen, M. Hallikainen, K. Majamaa, Mitochondrial DNA polymorphisms as risk factors for Parkinson's disease and Parkinson's disease dementia, Hum. Genet. 115 (2004) 29-35.

[11] A. Siitonen, M.A. Nalls, D. Hernández, J.R. Gibbs, J. Ding, P. Ylikotila, C. Edsall, A. Singleton, K. Majamaa, Genetics of early-onset Parkinson's disease in Finland: exome sequencing and genome-wide association study, Neurobiol. Aging 53 (2017) 195 e7-195.e10.

[12] K. Wang, M. Li, H. Hakonarson, ANNOVAR: functional annotation of genetic variants from high-throughput sequencing data, Nucleic Acids Res. 38 (2010) e164.

[13] P. Cingolani, A. Platts, L. Wang le, M. Coon, T. Nguyen, L. Wang, S.J. Land, X. Lu, D.M. Ruden, A program for annotating and predicting the effects of single nucleotide polymorphisms, SnpEff: SNPs in the genome of Drosophila melanogaster strain w1118; iso-2; iso-3, Fly. (Austin) 6 (2012) 80-92.

[14] P. Cingolani, V.M. Patel, M. Coon, T. Nguyen, S.J. Land, D.M. Ruden, X. Lu, Using Drosophila melanogaster as a model for genotoxic chemical mutational studies with a new program, SnpSift, Front. Genet. 3 (2012) 35.

[15] J. Bendl, J. Stourac, O. Salanda, A. Pavelka, E.D. Wieben, J. Zendulka, J. Brezovsky, J. Damborsky, PredictSNP: robust and accurate consensus classifier for prediction of disease-related mutations, PLOS Comput. Biol. 10 (2014) e1003440.

[16] L. Excoffier, H.E. Lischer, Arlequin suite ver 3.5: a new series of programs to perform population genetics analyses under Linux and Windows, Mol. Ecol. Resour. 10 (2010) 564-567.

[17] S. Ylönen, P. Ylikotila, A. Siitonen, S. Finnilä, J. Autere, K. Majamaa, Variations of mitochondrial DNA polymerase $\gamma$ in patients with Parkinson's disease, J. Neurol. 260 (2013) 3144-3149.

[18] T. Pulkes, C. Papsing, A. Thakkinstian, S. Pongpakdee, K. Kulkantrakorn, S. Hanchaiphiboolkul, S. Tiamkao, P. Boonkongchuen, Confirmation of the association between LRRK2 R1628P variant and susceptibility to Parkinson's disease in the Thai population, Park. Relat. Disord. 20 (2014) 1018-1021.

[19] C. Ran, L. Brodin, L. Forsgren, M. Westerlund, M. Ramezani, S. Gellhaar, F. Xiang, C. Fardell, H. Nissbrandt, P. Söderkvist, A. Puschmann, E. Ygland L. Olson, T. Willows, A. Johansson, O. Sydow, K. Wirdefeldt, D. Galter P. Svenningsson, A.C. Belin, Strong association between glucocerebrosidase mutations and Parkinson's disease in Sweden, Neurobiol. Aging 45 (2016) 212 e5-212.e11.

[20] X. Wu, K.-F. Tang, Y. Li, Y.-Y. Xiong, L. Shen, Z.-Y. Wei, K.-J. Zhou, J.-M. Niu, X. Han, L. Yang, G.-Y. Feng, L. He, S.-Y. Qin, Quantitative assessment of the effect of LRRK2 exonic variants on the risk of Parkinson's disease: a metaanalysis, Park. Relat. Disord. 8 (2012), 722e730.

[21] Y. Shu, J. Ming, P. Zhang, Q. Wang, F. Jiao, B. Tian, Parkinson-related LRRK2 mutation R1628P enables Cdk5 phosphorylation of LRRK2 and upregulates its kinase activity, PLoS One 11 (2016) e0149739.

[22] P. Volders, J. Van Hove, R.J.U. Lories, Ph. Vandekerckhove, G. Matthijs, R. De Vos, M.T. Vanier, M.F. Vincent, R. Westhovens, F.P. Luyten, Niemann-Pick Disease Type B: an unusual clinical presentation with multiple vertebral fractures, Am. J. Med. Genet. 109 (2002) 42-51.

[23] A. Anvret, M. Westerlund, O. Sydow, T. Willows, C. Lind, D. Galter, A.C. Belin, Variations of the CAG trinucleotide repeat in DNA polymerase gamma (POLG1) is associated with Parkinson's disease in Sweden, Neurosci. Lett. 485 (2010) $117-120$.

[24] N. Balafkan, C. Tzoulis, B. Müller, K. Haugarvoll, O.B. Tysnes, J.P. Larsen, L.A. Bindoff, Number of CAG repeats in POLG1 and its association with Parkinson disease in the Norwegian population, Mitochondrion 12 (2012) 640-643.

[25] Y.X. Gui, Z.P. Xu, W. Lv, H.M. Liu, J.J. Zhao, X.Y. Hu, Association of mitochondrial DNA polymerase $\gamma$ gene POLG1 polymorphisms with parkinsonism in Chinese populations, PloS One 7 (2012) e50086.

[26] J. Eerola, P.T. Luoma, T. Peuralinna, S. Scholz, C. Paisan-Ruiz, A. Suomalainen, A.B. Singleton AB, P.J. Tienari, POLG1 polyglutamine tract variants associated with Parkinson's disease, Neurosci. Lett. 477 (2010) 1-5.

[27] S.R. Bentley, J. Shan, M. Todorovic, S.A. Wood, G.D. Mellick, Rare POLG1 CAG variants do not influence Parkinson's disease or polymerase gamma function, Mitochondrion 15 (2014) 65-68.

[28] A.T. Rovio, D.R. Marchington, S. Donat, H.C. Schuppe, J. Abel, E. Fritsche, D.J. Elliott, P. Laippala, A.L. Ahola, D. McNay, R.F. Harrison, B. Hughes, T. Barrett, D.M. Bailey, D. Mehmet, A.M. Jequier, T.B. Hargreave, S.H. Kao, J.M. Cummins, D.E. Barton, HJ. Cooke, Y.H. Wei, L. Wichmann, J. Poulton, H.T. Jacobs, Mutations at the mitochondrial DNA polymerase (POLG) locus associated with male infertility, Nat. Genet. 29 (2001) 261-262. 